\title{
The Influence of Shadow Education on Cognitive Ability and Non-Cognitive Ability
}

\author{
Xiangyu Zhao \\ School of Economics, Jinan University, Guangzhou, China \\ Email: 415539099@qq.com
}

How to cite this paper: Zhao, X.Y. (2019) The Influence of Shadow Education on Cognitive Ability and Non-Cognitive Ability. Modern Economy, 10, 945-961. https://doi.org/10.4236/me.2019.103063

Received: February 23, 2019

Accepted: March 22, 2019

Published: March 25, 2019

Copyright $\odot 2019$ by author(s) and Scientific Research Publishing Inc. This work is licensed under the Creative Commons Attribution International License (CC BY 4.0).

http://creativecommons.org/licenses/by/4.0/

\begin{abstract}
Utilizing a nationally representative data set from China Education Panel Survey (CEPS), this study examines the effects of family factors and extra-curricular tutoring on Chinese students' cognitive ability and non-cognitive ability. Based on the method of Ordinary Least Square (OLS) and Propensity Score Matching (PSM), we find that family socioeconomic status (SES) has a significant positive impact on both cognitive and non-cognitive ability. At the same time, family relationships significantly boost students' non-cognitive ability. As for shadow education, we concluded that academic tutoring has a positive effect on students' cognitive ability, but it has no significant positive effect on non-cognitive ability, while the positive effect of interest tutoring on non-cognitive ability is greater than the negative influence effect on cognitive ability.
\end{abstract}

\section{Keywords}

Family Socioeconomic Status, Tutoring Class, Cognitive Ability, Non-Cognitive Ability

\section{Introduction}

With the development of social economy, the importance of individual comprehensive ability in the labor market has surpassed the academic qualifications to become the object of investigation by various employers. At the same time, it has become the objects inspected by individual employers. In the traditional environment of "Walras model", ability is interpreted as cognitive ability. The traditional human capital based on cognitive ability encountered challenges to explain the difference in income, such as how to explain the residuals of the Mincer income equation and the intergenerational income equation, etc. [1]. But with the development of psychology and personality psychology, personality 
traits were explored and measured, so that non-cognitive ability could emerged. Therefore, the new human capital theory including non-cognitive ability is widely recognized.

What factors affect cognitive and non-cognitive abilities, and how to improve the child's two abilities are what every family and every parent care about. There are many factors that can influence these two capabilities. Currently, most literature focus on family factors and school factors, but these studies of family factors are limited to family socioeconomic status (SES) while it ignores human factors, especially the emotional factors among family members. Parents concentrate on providing children with optimal living and learning material environment, but at the same time they may potentially bring incorrect values and negative emotions to their children, which must be backfire. As the saying goes, parents are the children's first teacher. Just because parents' attitudes and behaviors greatly influence their children's behavioral habits and personality shaping which would affect their cognitive ability and non-cognitive ability [2]. The new family education model should fully consider the impact of family environment on children's personality traits [3].

On the other hand, school characteristics also significantly affect adolescents' cognitive ability [4]. So the key middle schools in the provinces and municipalities are hot among the majority of students, while their parents take every means to help them. However, in China, the issue of the allocation of educational resources due to limited public education resources is widespread. In this case, tutoring as a form of education parallel to public education has become a global trend. At the same time, the increasing emphasis on the education of children in Chinese parents has led to a rapid expansion of tutoring in recent years. Therefore, elite education such as Interest tutoring, parent-child interaction, equestrian and golf quickly won the favor of the majority of Chinese parents. In 2016, Market size of education industry exceeded 800 billion, and the number of students participating in tutoring reached 137 million (From the "Investigation Report on the Status of Teachers in China's Counseling Education Industry and Counseling Institutions"). Does Extra-curricular tutoring improve children's ability? Does it make sense for parents to sign up for various training institutions for their children? Most of the existing researches in China are based on the perspective of educational equity or the personal benefits to evaluate the impact of extra-curricular tutoring, but the literatures about how extra-curricular tutoring, including interest tutoring and academic tutoring, affects participants' cognitive ability and non-cognition ability is rare.

Based on the above analysis, this paper uses data set from China Education Panel Survey (CEPS) to explore the effects of family factors and extra-curricular tutoring on Chinese students' cognitive ability and non-cognitive ability. It aims to enrich research on the influence of family factors and tutoring on human capital. And it is expected to play a certain reference in theoretical mechanism and policy practice. Specifically, this article focuses on these issues: 1) How family 
factors affect adolescents' cognitive ability and non-cognitive ability? 2) Whether students will show differences in cognitive and non-cognitive abilities due to the participation of shadow education.

The article is organized as follows: The first part is the introduction. This part expounds the research background and significance of the thesis and combs the related literature review at home and abroad, then establishes the research ideas and research contents of this paper, and presents the structure of the article. The second part is data, variables and empirical models. First, this section describes the data sources and how to deal with them. Next, the relevant variables are defined and described. Finally, an empirical model is presented, including an improved multiple linear regression model and a PSM model. The third part is an empirical analysis. In this section we will present important regression results and analyze them. The fourth part is the conclusions and recommendations. Through the empirical analysis in the previous section, we will summarize the important conclusions of this article in this section and present some inspirations and suggestions for the conclusion.

\section{Literature Review and Theoretical Assumptions}

In recent years, with the continuous development of human capital theory and the continuous improvement of data content and structure, the research on cognitive ability and non-cognitive ability at home and abroad has been deepening. Not only does the return on investment of human capital attracts a large number of scholars, but the measurement of cognitive ability and non-cognitive ability to study its influencing factors is also of great interest to the academic community.

\subsection{Cognitive Ability and Non-Cognitive Ability}

In the mid- $20^{\text {th }}$ century, the human capital theory pioneered by Theodore $\mathrm{W}$. Schultz, Gary Becker, and Jacob Mincer proposed that ability can be improved and it can affect personal income. However, what the ability is become a blind spot for research. Subsequently, traditional human capital dominated by cognitive ability emerged. Cognitive ability mainly includes language, reading, writing and calculation, and logical ability [5]. Numerous studies in labor economics have shown that cognitive ability has a significant impact on educational access [6] [7] and income levels [8] [9]. Domestic scholars have also analyzed the influence of arithmetic reasoning ability and mathematical computing ability on personal income based on the standard Mincer equation [10]. At the same time, cognitive differences are also reflected in financial market participation [11]. Since cognitive ability is so important, researchers will naturally pay more attention to its social reproduction and influencing factors. Bowles \& Gintis (1976) believe that cognitive ability has intergenerational inheritance, and to a large extent, children's cognitive ability comes from the inheritance of parents' cognitive ability [12]. Later, there was a large body of literature indicating that the influencing factors of cognitive ability were mainly concentrated at the family level [13] 
and at the school level [4].

However, in the process of cognitive ability research, researchers found that cognitive ability is not satisfactory in explaining income differences. which indicates that there are other factors in addition to cognitive ability affecting income [14] [15]. Xu Duoduo [16] found that education not only cultivates cognitive ability but also cultivates other abilities [16], and further discovers that when science and technology progress or economic development is uneven, some non-cognitive features such as curiosity and risk preference that are not related to cognition will be advantageous to success. There is no lack of research on personality characteristics in the field of psychology, but in the field of economics, the research on non-cognitive fields is relatively lagging behind because of measurement. Later, the Big Five Personality Measurement method by personality psychologists, due to its comprehensive advantages, gradually developed and was widely used to measure non-cognitive ability. Since then, research on non-cognitive ability has gradually begun. Zhou Jinyan [1] exploring the economic value and investment of non-cognitive ability through combing and summarizing the development of human capital theory. He Junzi [17] also studied the educational return rate of cognitive ability and non-cognitive ability based on the International Adult Competence Assessment Project [18]. The research on the influencing factors of non-cognitive ability mainly focuses on family background [18], cultural capital [19] and pre-school education [20].

\subsection{Family Factors, Cognitive Ability and Non-Cognitive Ability}

Scholars have found that family-level factors have a significant impact on cognitive ability and non-cognitive ability when studying the influencing factors of ability. Anger and Schnitzlein [21] proposed the importance of family background to the formation of cognitive and non-cognitive abilities based on the relationship between brothers and sisters. At the same time, the study found that parents' social and economic status not only has a direct impact on their children's cognitive ability and non-cognitive ability, but also indirectly affects these two abilities through parental involvement and student self-education [22]. In addition, there is also a mainstream theory that emphasizes the importance of cultural capital as a mediator of family background affecting cognitive and non-cognitive abilities. SES affects cognitive and non-cognitive abilities by influencing the participation of cultural activities, the amount of family collections, and extracurricular learning [23]. Cunha and Heckman [24] proposed the concept of complementarity between self-productivity and human capital investment, explained the formation of skills and emphasized the importance of early human capital investment. Later, some scholars also found that family background affects cognitive ability and non-cognitive ability by affecting the acquisition of preschool education [25]. The family background largely determines the opportunities and ways to develop children's cognitive and non-cognitive abilities. Families with superior conditions can choose better schools for their children to receive better 
education, and the quality of education is closely related to students' cognitive and non-cognitive abilities [26].

However, most of the literature uses the level of parental education, family economic status, and parental status in the measurement of family factors, mainly focusing on the consideration of family economic and social status. But at the family level, there are other factors besides SES, such as family relationship between family members. Family relationships are reflected in the communication between family members. The interaction between parents and the communication between parents and children affects the personality characteristics of children not only in the content of communication, but also in the form and emotion of communication [2] [27]. It can be seen that the child's "first teacher" helps children acquire cognitive skills as well as their children's non-cognitive ability and outlook on life and values. The existing literature is not comprehensive enough in the measurement of non-cognitive ability, which just include self-efficacy or social interaction. In view of this, this article puts forward the following assumptions after improving the indicators of non-cognitive ability:

H1: Family socioeconomic status has a significant impact on children's cognitive ability and non-cognitive ability.

H2: Relationships between family members have a significant impact on a child's non-cognitive ability.

\subsection{Shadow Education, Cognitive Ability and Non-Cognitive Ability}

Private supplementary tutoring is to follow the formal education system, so the content of tutoring changes with the content of the curriculum of the formal education system and the scale expands with the expansion of the formal education system, which is called "shadow education" [28] [29]. Studies have included extracurricular learning as a measure of cultural capital to emphasize the importance of cultural capital. However, the systematic and continuous involvement of shadow education in the school education has shaken the explanatory power of cultural capital theory, and there is a reciprocal relationship between them [30]. In the process of intergenerational inheritance of family capital, both school education and shadow education have played an important channel role, thus establishing a dual social reproduction mechanism of school education and shadow education [31]. As the most important performance of cognitive ability, academic record is not only valued by parents, but also paid attention by scholars. Li Jiali [32] Based on the Wisconsin model analyzed that the family background indirectly affects shadow education participation through the mediation of educational expectation, and there is an inverse U-linear relationship between shadow education participation time and student achievement. Shadow education has an impact on performance, which makes students have a sense of accomplishment and self-confidence. According to Self-efficacy theory, these senses of achievement and self-confidence can influence individual emotions and decision-making processes and thus affect non-cognitive ability [33]. 
In summary, the previous research on shadow education mainly raised the issue of educational fairness through the examination of the impact of achievement. However, nowadays, with the content of tutoring and its form becoming diverse, its influence on individuals is multi-faceted and deep which makes it necessary to explore the impact of extra-curricular tutoring on students' cognitive ability and non-cognitive ability. Since academic tutoring is a supplement to the school curriculum and mostly focuses on language and mathematics training, academic tutoring is closely related to cognitive ability. On the one hand, interest counseling is mostly based on their own interests and hobbies, and people with the same hobbies are more likely to get along with each other, so individuals are satisfied with both personal and interpersonal aspects. Moreover, the form and content of the interest courses, learning methods, etc. also enable students to broaden their horizons and divergence of thinking; on the other hand, mastering relevant skills makes students more confident in their daily learning life. According to the theory of self-efficacy, successful learning experiences and mastery of skills improve students' self-efficacy. Therefore, the following assumptions are made:

H3: Academic tutoring has a significant impact on cognitive ability.

H4: Interest tutoring has a significant impact on non-cognitive ability.

\section{Data, Variables and Methods}

\subsection{Data}

The data in this paper is from the baseline survey for the 2013-2014 academic year of China Education Panel Survey (CEPS). The survey starting with two cohorts-the $7^{\text {th }}$ and $9^{\text {th }}$ graders and applying a stratified, multistage sampling design with probability proportional to size (PPS), randomly selecting a school-based, nationally representative sample of approximately 20,000 students in 438 classrooms of 112 schools in 28 county-level units in mainland China. The survey included not only family status, school situation, and Extra-curricular tutoring, but also a comprehensive cognitive test and relatively detailed personality test for students, so it is particularly suitable for this study. Then the paper selects student questionnaire data and school questionnaire data and matches them. We usually ignore missing values in the article.

\subsection{Variables}

The explanatory variables of this study are cognitive ability and non-cognitive ability. For cognitive ability, this study used CEPS data and used a three-parameter IRT model to estimate the total score of the cognitive ability test as a measure of cognitive ability. CEPS designed a set of cognitive ability test questions for students in the seventh and ninth grades. The test content does not involve the specific knowledge given by the school, but measures the cognition from the three dimensions of language, graphics, computing and logic. And it has the characteristics of international comparability and national standardization. For non-cognitive 
ability, this study adopts the "Big Five" model based on personality psychology, which is based on four aspects: conscientiousness, self-efficacy, social interaction, and emotional stability. The higher the score, the stronger the non-cognitive ability. Each of these aspects was obtained by principal component analysis of the relevant questions in the questionnaire. The details are shown in Table 1.

The core explanatory variables of this study are family factors and participation in shadow education. Family factors include family socioeconomic status and family membership. In this study, the principal component factor analysis of the parents' highest education (No education $=1$, primary school $=2$, junior high school $=3$, technical secondary school/technical school $=4$, vocational high school $=5$, high school $=6$, college degree $=7$, university undergraduate $=8$, graduate student and above $=9$ ), the highest occupational status of parents, and the current family economic conditions were used to obtain quantitative indicators of family socioeconomic status. Family membership is measured by "How is your relationship with your mother? Not close $=1$, generally $=2$, very close $=3$ ", "How is your relationship with Dad? Not close to $=1$, generally $=2$, very close $=$ 3 ", "My parents have a good relationship? Not like this $=1$, this is $=2$ ". Whether to participate in shadow education consists of whether to participate in cultural class counseling (including Olympics, general mathematics, Chinese, English) and whether to participate in interest class counseling (including painting, calligraphy, musical instruments, dance, chess, sports), both of which are dummy

Table 1. Non-cognitive ability measurement.

\begin{tabular}{|c|c|c|}
\hline conscientiousness & $\begin{array}{l}\text { Even if the body is a little uncomfortable, or other reasons can stay at home, } \\
\text { I will still try my best to go to school. }\end{array}$ & $\begin{array}{l}\text { Totally disagree }=1, \text { not agree }=2, \\
\text { compare agree }=3, \text { fully agree }=4\end{array}$ \\
\hline & $\begin{array}{l}\text { Even if I don't like my homework, I will try my best to do it. } \\
\text { Even if my homework takes a long time to finish, I will try my best to do it. }\end{array}$ & \\
\hline self-efficacy & $\begin{array}{l}\text { I can clearly express my opinion. } \\
\text { I am very responsive } \\
\text { I can learn new knowledge very quickly } \\
\text { I am curious about new things. }\end{array}$ & $\begin{array}{l}\text { Totally disagree }=1, \text { not agree }=2, \\
\text { compare agree }=3, \text { fully agree }=4\end{array}$ \\
\hline social interaction & $\begin{array}{l}\text { Most of the classmates are very good to me. } \\
\text { I think that I am easy to get along with others. } \\
\text { I am in a good class. } \\
\text { I often participate in activities organized by schools or classes. } \\
\text { I am very close to the people in this school. }\end{array}$ & $\begin{array}{l}\text { Totally disagree }=1, \text { not agree }=2, \\
\text { compare agree }=3, \text { fully agree }=4\end{array}$ \\
\hline emotional stability & $\begin{array}{l}\text { The frequency of depression in the past seven days } \\
\text { Frequency of depression in the past seven days } \\
\text { The frequency of unhappy in the past seven days } \\
\text { The frequency of feeling that life has no meaning in the past seven days } \\
\text { The frequency of pessimism in the past seven days }\end{array}$ & $\begin{array}{l}\text { Always }=1 \text {, often }=2 \text {, sometimes } \\
=3 \text {, rarely }=4 \text {, never }=5\end{array}$ \\
\hline
\end{tabular}


variables ( participation $=1$, no participation $=0$ ).

In addition, other control variables include gender (male $=1$ ), height, number of siblings, teacher attention, progress on peers, and participation in preschool education. The teacher's attention is measured by the praise, or questioning of the students in the classroom by the language, mathematics, and English teachers. The progress on peers is obtained by the ratio of good friends' performance (good grades, hard work, want to go to college) and degraded performance (violation of school discipline, frequent visits to Internet cafes or game halls, dropouts). Whether to participate in pre-school education is measured by whether you have been in kindergarten or preschool before the age of 3 (yes $=1$ ).

The sample mean and its difference test are shown in the following Table 2.

\subsection{Equations}

This paper conducts an empirical analysis in two stages: In the first stage, based on the classical multiple regression model (MLR), the influence of family factors and tutoring on cognitive ability and non-cognitive ability is estimated. Because the research object is middle school students, the school characteristics factors will affect the level of individual cognitive ability and non-cognitive ability to a large extent. Even if the variables such as teacher attention and progress on the companion are controlled, there are still unobservable school characteristics. Therefore, the school ID dummy variable is constructed to fix the school factor

Table 2. Variable descriptive statistics (Classify samples by participating in Academic tutoring).

\begin{tabular}{|c|c|c|c|c|c|}
\hline & \multicolumn{2}{|c|}{$\begin{array}{l}\text { Academic tutoring } \\
\text { (No) }\end{array}$} & \multicolumn{2}{|c|}{$\begin{array}{c}\text { Academic tutoring } \\
\text { (Yes) }\end{array}$} & \multirow{2}{*}{$\begin{array}{c}\text { Difference } \\
\text { between group }\end{array}$} \\
\hline & Sample size & Mean & Sample size & Mean & \\
\hline \multicolumn{6}{|l|}{ Variables } \\
\hline Cognitive ability & 12,911 & -0.107 & 6576 & 0.209 & $-0.316^{* * *}$ \\
\hline Non-cognitive ability & 11,457 & -0.221 & 5939 & 0.583 & $-0.803^{\star * *}$ \\
\hline Academic tutoring & 12,911 & 0 & 6576 & 1 & -1 \\
\hline Interest tutoring & 12,911 & 0.189 & 6576 & 0.398 & $-0.208^{\star \star \star}$ \\
\hline SES & 12,911 & -0.301 & 6576 & 0.590 & $-0.891^{\star * *}$ \\
\hline Relationship between parents & 12,341 & 2.728 & 6357 & 2.759 & $-0.031^{\star * *}$ \\
\hline Relationship with your mother & 12,853 & 2.683 & 6539 & 2.744 & $-0.060^{* * *}$ \\
\hline Relationship with your father & 12,825 & 2.566 & 6532 & 2.594 & $-0.028^{\star \star \star}$ \\
\hline Gender & 12,911 & 0.529 & 6576 & 0.489 & $0.040^{* * *}$ \\
\hline Height & 12,460 & 160.9 & 6421 & 162.9 & $-1.978^{\star \star \star}$ \\
\hline Number of siblings & 12,911 & 0.857 & 6576 & 0.504 & $0.353^{\star * *}$ \\
\hline Teacher attention & 12,628 & 15.02 & 6455 & 16.07 & $-1.043^{\star \star \star}$ \\
\hline Progress on peers & 12,511 & 2.209 & 6377 & 2.414 & $-0.205^{\star * *}$ \\
\hline Preschool education & 12,816 & 0.766 & 6519 & 0.862 & $-0.095^{\star * *}$ \\
\hline
\end{tabular}

Note: ${ }^{* *} \mathrm{p}<0.01,{ }^{* *} \mathrm{p}<0.05,{ }^{*} \mathrm{p}<0.1$. 
in order to reduce the endogenous bias of the MLR model. The equation is as follows:

$$
y_{i}=\beta_{0}+\beta_{1} x_{1 i}+\beta_{2} x_{2 i}+\gamma \text { control }_{i}+u_{j}+\varepsilon_{i}
$$

$i$ and $j$ represent the $\mathrm{i}$-th student and the $\mathrm{j}$-th school. $y_{i}$ indicates the cognitive or non-cognitive ability of the i-th student. $x_{1 i}$ indicates whether the i-th student participates in the cultural class counseling, $x_{2 i}$ indicates whether the i-th student participates in the interest class counseling. control $_{i}$ is a series of control variables that affect the cognitive and non-cognitive abilities of the i-th student. It includes family socioeconomic conditions, relationships between parents, relationships with mothers, relationships with fathers, gender, height, number of siblings, teacher attention, progress on peers, and participation in preschool education. $\gamma$ is a coefficient estimation matrix, $u_{j}$ indicates school factors, $\varepsilon_{i}$ is a random disturbance term.

Because individuals choose whether to participate in cultural class counseling or interest class counseling is non-random, and OLS regression will inevitably lead to endogenous bias due to sample selection problems, so we use propensity score matching (PSM) in the second stage to derive the "net effect" of tutoring. First, we use logit regression to score the propensity to receive intervention (in this article, participate in the culture class/interest class counseling); then, the treatment group individuals and the control group individuals are matched by nearest neighbor matching; the balance of matching is tested. Finally, the average intervention effect of cognitive and non-cognitive ability in cultural class counseling and interest class counseling is obtained. Taking the influence of cultural tutoring on cognitive ability as an example, the model is built as follows:

$$
\begin{gathered}
\ln \left[\frac{p_{i}\left(x_{1 i}=1\right)}{1-p_{i}\left(x_{1 i}=1\right)}\right]=\beta_{0}^{*}+\beta_{1}^{*} x_{2 i}+\gamma^{*} \text { control }_{i}+D_{t}+\varepsilon^{*} \\
\mathrm{ATT}= \\
E\left\{y(1) \mid x_{1 i}=1, p_{i}\left(x_{1 i}=1\right)\right\}-E\left\{y(0) \mid x_{1 i}=0, p_{i}^{\prime}\left(x_{1 i}=1\right)\right\} \\
p_{i}\left(x_{1 i}=1\right)-\text { caliper }<p_{i}^{\prime}\left(x_{1 i}=1\right)<p_{i}\left(x_{1 i}=1\right)+\text { caliper }
\end{gathered}
$$

Equation (1) is a logistic regression model, in which $p_{i}\left(x_{1 i}=1\right)$ is the propensity value of the participation in the cultural class counseling, $\gamma^{*}$ is the control variable coefficient matrix, and $D_{t}$ is the region where the school is located. Equation (2) is the average intervention effect model. $E\left\{y(1) \mid x_{1 i}=1, p_{i}\left(x_{1 i}=1\right)\right\}$ is the recognition when participating in the cultural class counseling under the condition of probability $E\left\{y(0) \mid x_{1 i}=0, p_{i}^{\prime}\left(x_{1 i}=1\right)\right\}$ is the observation value of the cognitive ability when participating in the cultural class counseling with $p_{i}^{\prime}\left(x_{1 i}=1\right)$ but not participating in the cultural class counseling. Equation (3) is a neighbor matching method model, in this study caliper $=0.05$.

\section{Results Analysis and Hypothesis Testing}

\subsection{Results Based on OLS}

We added robust in the regression to eliminate heteroscedasticity to improve the 
robustness of the results. Table 3 lists the OLS regression results after controlling the school effect. As far as family factors are concerned, the SES has a significant positive impact on both cognitive and non-cognitive abilities. This conclusion is consistent with most previous studies. However, the relationship between family members has different effects on cognitive ability and non-cognitive ability. Specifically, family relationships, including relationships between parents, relationships between children and mothers, and relationships between children and fathers, have no significant effect on cognitive ability, but have significant positive effects on non-cognitive ability. The more intimate the family members are, the better the non-cognitive ability of the child. Up to here, Hypothesis 1 and Hypothesis 2 are verified.

In the shadow education, after controlling other variables such as family factors, the results show that students who participate in academic tutoring perform better in cognitive ability than those who do not participate in, but there are no Significant differences in non-cognitive ability. The results here preliminarily verify the hypothesis 3 . The participation of interest class counseling not only has a significant positive impact on non-cognitive ability but also has a significant negative impact on cognitive ability. The reason is that in the context of exam-oriented education, the emphasis on cultural classes is far greater than that of interest classes. Although the participation of interest classes has improved the non-cognitive ability of middle school students, it also takes up a certain

Table 3. Variable descriptive statistics (Classify samples by participating in Interest tutoring).

\begin{tabular}{|c|c|c|c|c|c|}
\hline & \multicolumn{2}{|c|}{ Interest tutoring (No) } & \multicolumn{2}{|c|}{ Interest tutoring (Yes) } & \multirow{2}{*}{$\begin{array}{c}\text { Difference } \\
\text { between groups }\end{array}$} \\
\hline & Sample size & Mean & Sample size & Mean & \\
\hline \multicolumn{6}{|l|}{ Variables } \\
\hline Cognitive ability & 14,428 & -0.0170 & 5059 & 0.0490 & $-0.066^{\star * *}$ \\
\hline Non-cognitive ability & 12,919 & -0.188 & 4477 & 0.750 & $-0.938^{\star * *}$ \\
\hline Academic tutoring & 14,428 & 0.275 & 5059 & 0.517 & $-0.242^{\star \star \star *}$ \\
\hline Interest tutoring & 14,428 & 0 & 5059 & 1 & -1 \\
\hline SES & 14,428 & -0.184 & 5059 & 0.525 & $-0.710^{\star * \star}$ \\
\hline Relationship between parents & 13,854 & 2.735 & 4844 & 2.749 & -0.0140 \\
\hline Relationship with your mother & 14,371 & 2.687 & 5021 & 2.752 & $-0.066^{\star * *}$ \\
\hline Relationship with your father & 14,343 & 2.561 & 5014 & 2.616 & $-0.055^{\star * \star}$ \\
\hline Gender & 14,428 & 0.533 & 5059 & 0.466 & $0.066^{\star * *}$ \\
\hline Height & 13,975 & 161.4 & 4906 & 162.2 & $-0.739^{\star * \star}$ \\
\hline Number of siblings & 14,428 & 0.786 & 5059 & 0.602 & $0.184^{\star * *}$ \\
\hline Teacher attention & 14,148 & 15.11 & 4935 & 16.15 & $-1.042^{\star * \star}$ \\
\hline Progress on peers & 14,010 & 2.244 & 4878 & 2.376 & $-0.132^{\star * *}$ \\
\hline Preschool education & 14,326 & 0.789 & 5009 & 0.826 & $-0.038^{\star * *}$ \\
\hline
\end{tabular}

Note: ${ }^{* *} \mathrm{p}<0.01,{ }^{* *} \mathrm{p}<0.05,{ }^{*} \mathrm{p}<0.1$ 
amount of academic study time, which makes them relatively backward in language and mathematics. Hypothesis 4 is also initially verified here. Of course, in the second phase of PSM analysis we will continue to focus on the impact of shadow education on cognitive and non-cognitive abilities.

At the same time, the control variables are also worthy of attention. We can see from the regression results that boys perform better in cognitive ability, but there is no significant gender difference in non-cognitive ability; Height as an important indicator of personal health status has a significant positive correlation with cognitive ability; The number of family brothers and sisters is also an important factor influencing cognitive ability and non-cognitive ability. After all, the number of brothers and sisters directly determines the economic capital and family care that each person receives when the family economic conditions are certain. The results in the table also show that the more the number of siblings, the lower the cognitive and non-cognitive ability of the individual; The teacher's attention and the progress of the peers also have a significant positive impact on cognitive ability and non-cognitive ability; the participation of preschool education has an important impact on the acquisition of individual cognitive ability and non-cognitive ability. Therefore, preschool education has received extensive attention in academia (Table 4).

\subsection{Results Based on PSM}

First of all, when we used the logit model to score the two types of extracurricular tutoring, we found that the tutoring of academic classes and the tutoring of interest classes are often synchronized, which means that students will choose both types of tutoring in most cases. SES and the number of siblings significantly influence the participation of both types of counseling. If we assume that intermediaries have a mediating effect, it explains the impact of SES and the number of siblings on the two abilities to some extent. In addition, we also found that family relationships only affect the participation of Interest tutoring, perhaps because interest tutoring relies on communication between children and parents about interest development. Girls are more likely to participate in tutoring than boys. The peer effect is reflected in the decision-making of the academic tutoring. At the same time, the teacher's attention has a positive impact on the participation of students' tutoring. After all, people are eager to be concerned.

Next, we used the nearest neighbor matching method (caliper $=0.05$ ) to match the processing group and the control group and tested the balance of the data. It turns out that the match balances the data better. Due to space limitations, we explain the balance test results by taking the influence of academic tutoring on cognitive ability as an example, the normalized deviation (\%bias) of all variables after matching is less than $10 \%$, and the results of the t-test do not reject the null hypothesis that there is no systematic difference between the treatment group and the control group. Comparing the results of the unmatched results, we can see that the standard deviation of all variables is greatly reduced. It 
Table 4. The influence of family factors and shadow education on cognitive ability and non-cognitive ability.

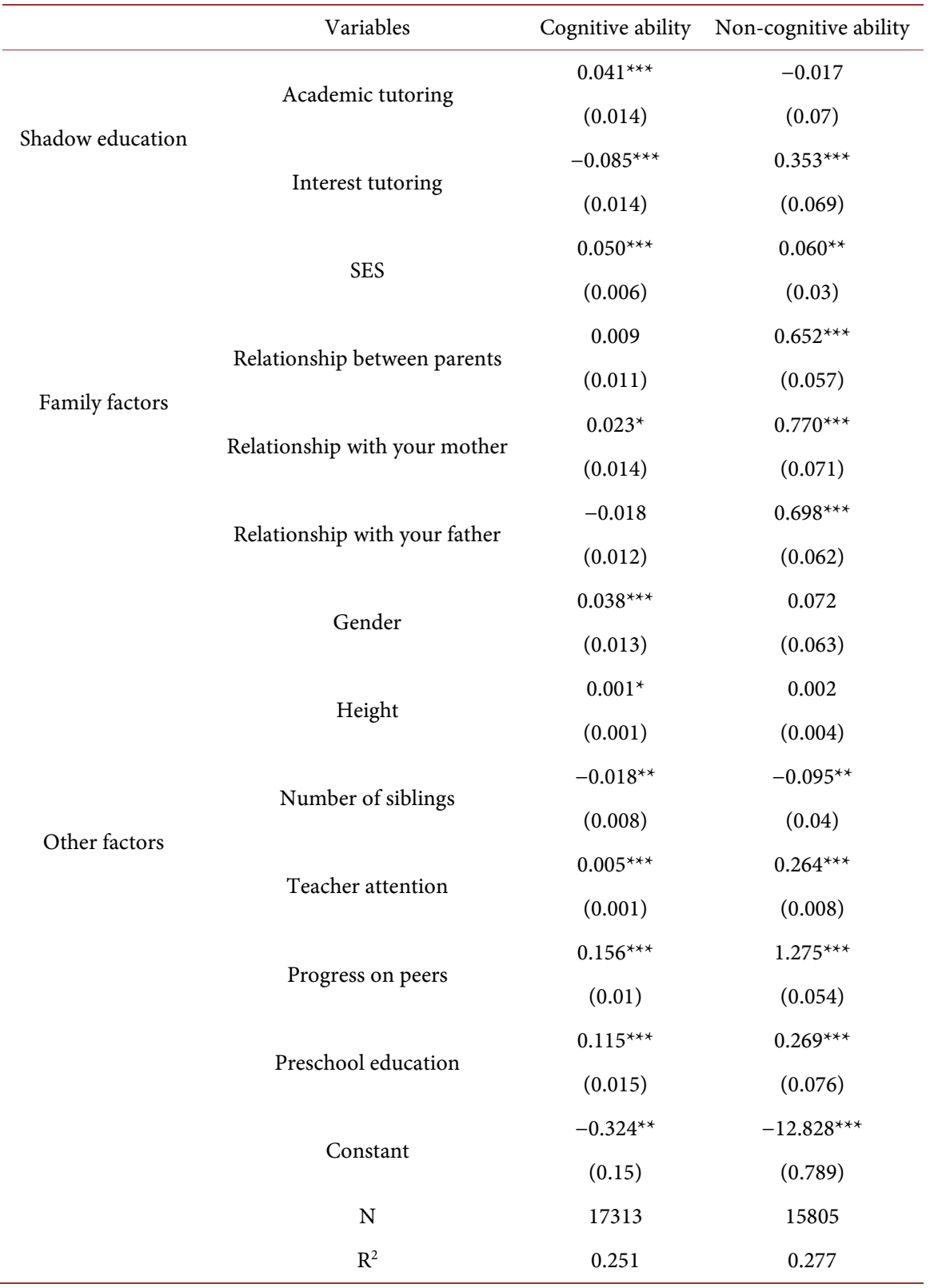

Note: Robust standard error in brackets, ${ }^{*} \mathrm{p}<0.10,{ }^{* *} \mathrm{p}<0.05,{ }^{* * *} \mathrm{p}<0.01$.

can be seen that the variables are balanced between the experimental group and the control group after matching. It can also be seen intuitively from Figure 1 that most of the observations are within the common value range (On support) with only a small sample loss. The above balance test results provide some support for the reliability of the PSM estimation results.

After the balance test, we calculated the average processing effect of the cognitive and non-cognitive ability of the academic tutoring and interest tutoring. From the regression results in Table 5, we can draw the following conclusions: Academic tutoring has a significant positive impact on cognitive ability, while 


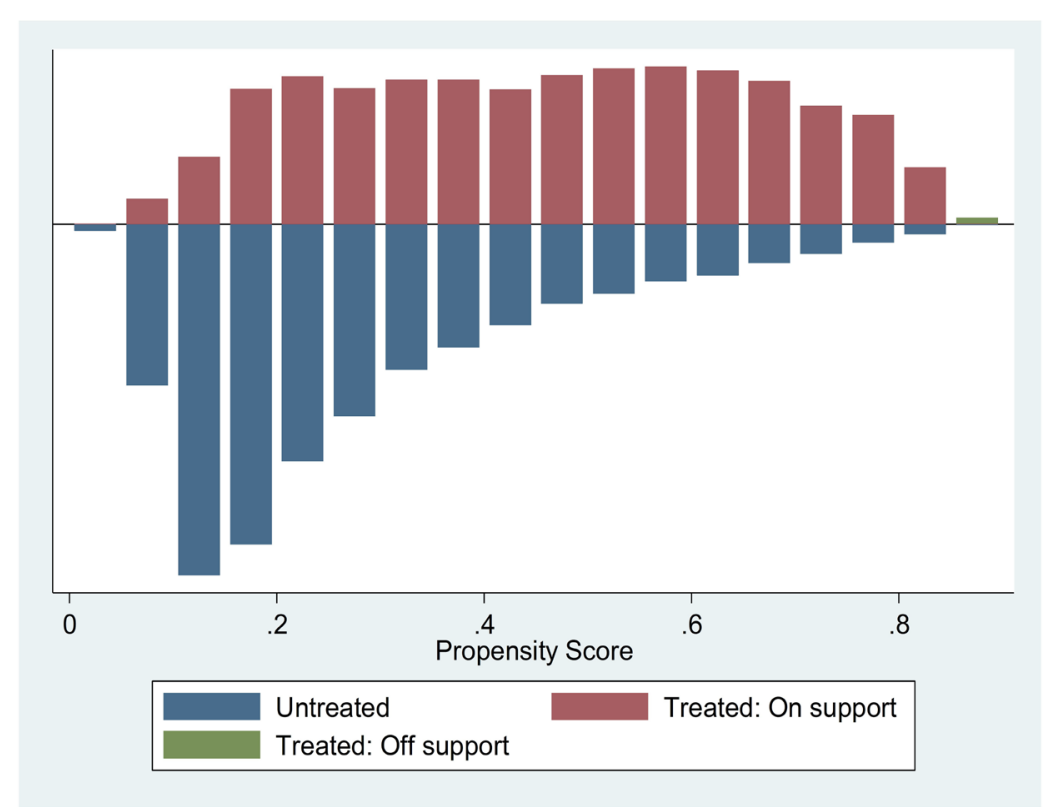

Figure 1. Common value range of propensity scores.

Table 5. Estimation results based on PSM.

\begin{tabular}{ccc}
\hline & Cognitive ability & Non-cognitive ability \\
\hline \multirow{2}{*}{ Academic tutoring } & $0.060^{* * *}$ & 0.004 \\
& $(0.021)$ & $(0.108)$ \\
Interest tutoring & $-0.105^{* * *}$ & $0.459^{* * *}$ \\
& $(0.022)$ & $(0.11)$ \\
\hline
\end{tabular}

Note: The ATT reported in the table based on the nearest neighbor matching method, Standard error in parentheses, ${ }^{*} \mathrm{p}<0.10,{ }^{* *} \mathrm{p}<0.05,{ }^{* * *} \mathrm{p}<0.01$.

the effect on non-cognitive ability is not significant; Interest tutoring has a significant negative impact on cognitive ability, but it has a significant positive impact on non-cognitive ability. From the perspective of coefficient size, the influence coefficient of interest class counseling on non-cognitive ability is 0.459 , which is greater than the negative coefficient of cognitive ability of 0.105 . This shows that the benefits of interest class counseling outweigh the disadvantages. The conclusions drawn by the PSM are consistent with the conclusions of the OLS estimates above, and Hypothesis 3 and Hypothesis 4 are further validated.

\section{Conclusions and Enlightenment}

After the above empirical analysis, we draw the following conclusions: 1) Generally speaking, the higher the socioeconomic status of the family, the stronger the cognitive and non-cognitive ability of the child, and the SES is mainly reflected in the parental education, occupational status and family economic conditions. 2) The relationship between parents and the relationship between children and parents as an important embodiment of the family's humanistic environment has an important impact on the child's non-cognitive ability. The more intimate 
the relationship between family members, the stronger the child's non-cognitive ability. 3) Students who participated in academic tutoring had higher cognitive ability scores than those who did not participate, but the positive impact on non-cognitive ability was not significant. 4) Students who participated in the tutoring of interest classes showed stronger non-cognitive ability than those who did not participate. On the contrary, in terms of cognitive ability, students who participate in interest class counseling have weak cognitive ability.

In addition, we also found that teacher attention as a factor at the school level has an important impact on students' cognitive and non-cognitive abilities. Under the condition of limited family resources, the more the number of siblings in the family, the more unfavorable the child's cognitive ability and non-cognitive ability. The peer effect is reflected in the individual's cognitive ability and noncognitive ability. The higher the progress of the peer, the stronger the child's cognitive ability and non-cognitive ability. The involvement of preschool education has also had an important impact on cognitive and non-cognitive abilities, and it has received widespread attention.

The above conclusions also give us a lot of inspiration:

1) Superior family conditions do provide more opportunities and ways for children to develop their abilities, but parents' love for their children is not only reflected in the material aspect. Building a harmonious human environment is especially important for the development of children's abilities. Parents work hard to increase their income and provide their children with more superior material conditions, but they ignore the communication and companionship of their children. As a child, you may not be able to choose your own origin, but you have the right to choose which kind of family atmosphere to grow. Obviously, as a parent, you cannot deprive your child of this right. Communicating between parents in a harmonious way will allow children to better understand marriage and family, and also teach them how to get along with others. Communicating more with your children will make them feel that they are being cared for and valued, which will make them more confident on the road to growth.

2) Due to the long-term continuous involvement of shadow education in student learning and daily life, the influence of shadow education on students' cognitive ability and non-cognitive ability must be paid attention to. Academic tutoring does have a positive effect on the improvement of students' cognitive ability, but if you only study language, mathematics and foreign languages, the coaching effect will inevitably decline. On the one hand, academic counseling takes up the time that they should be relaxed, which makes their learning efficiency less. On the other hand, there is no purposeful counseling that makes cognitive improvement limited. However, the tutoring of interest can better regulate academic tutoring. It not only allows students to work and rest to improving their learning efficiency, but also cultivates their non-cognitive ability. Therefore, parents should pay more attention to cultural classes and communi- 
cate with their children to choose an interest class that suits their interests.

With the development of society, the talents cultivated under the examination-oriented education system can no longer meet the needs of the new era. Therefore, the school should pay attention to the quality training and moral education of students in school. Doing a good job of supervision is not only a difficult point but also a breakthrough point for the education department. On the one hand, it is necessary to guide the teachers to focus on the students, and to avoid the teachers neglecting the care of the students in the school due to the out counseling. On the other hand, the external counseling institutions must be strictly examined. At the same time, relevant departments should actively guide the off-campus counseling institutions to carry out teaching innovation, and take students' personal development as the guide to cultivate students' discovery, creativity and learning ability. In summary, whether it is the education sector, educational institutions, or parents, they have to take responsibility for nurturing the next generation of the motherland, even though this responsibility is heavy.

\section{Conflicts of Interest}

The author declares no conflicts of interest regarding the publication of this paper.

\section{References}

[1] Zhou, J.Y. (2015) Expansion of the Connotation of Human Capital: Economic Value and Investment of Non-Cognitive Capabilities. Peking University Education Review, 13, 78-95.

[2] Meng, C.Y. (2015) Analysis of the Influence of Family Environment on Students' Personality Modeling. New Education Era.

[3] Lei, L., Wang, Z.Y., Liu, H.Y. and Zhang, L. (2002) Parent-Child Communication of Junior High School Students and Its Relationship with Family Environment System and Social Adaptation. Applied Psychology, 14-20.

[4] Jiang, Q.C. (2017) Family Background, School Quality and Cognitive Skills Differences between Urban and Rural Youth. Education and Economics, No. 140, 23-32.

[5] Farkas, G. (2003) Cognitive Skills and Noncognitive Traits and Behaviors in Stratification Processes. Annual Review of Sociology, 29, 541-562. https://doi.org/10.1146/annurev.soc.29.010202.100023

[6] Griliches, Z. and Mason, W.M. (2000) Education, Income and Ability. Journal of Political Economy, 3, 74.

[7] Spence, M. (1973) Job Market Signaling. Quarterly Journal of Economics, 87, 355-374. https://doi.org/10.2307/1882010

[8] Blackburn, M.K.L. and Neumark, D. (1993) Omitted-Ability Bias and the Increase in the Return to Schooling. Journal of Labor Economics, 11, 521-544.

https://doi.org/10.1086/298306

[9] John, F. Skill and Consequences for Racial Disparity and Returns to Schooling. Malcolm Wiener Center for Social Policy.

[10] Zhang, X.Y. and Du, L.Q. (2017) Cognitive Ability, Quality Comparable Education 
and Income-Based on Empirical Analysis of the Expansion of Mincer's Equation. World Economic WeChat, No. 6, 39-55.

[11] Meng, Y.J. (2014) Cognitive Ability and Family Asset Selection. Economic Research, No. S1, 132-142.

[12] Bowles, S., Gintis, H. and Osborne, M. (2001) The Determinants of Earnings: A Behavioral Approach. Journal of Economic Literature, 39, 1137-1176. https://doi.org/10.1257/jel.39.4.1137

[13] Figlio, D., Guryan, J., Karbownik, K. and Roth, J. (2014) The Effects of Poor Neonatal Health on Children's Cognitive Development. American Economic Review, 104, 3921-3955. https://doi.org/10.1257/aer.104.12.3921

[14] Le, J.J. and Hu, B.W.(2017) The Impact of Non-Cognitive Ability on Workers' Wage Income. China Population Science, No. 4, 68-78.

[15] Huang, G.Y. and Xie, Y. (2017) The Impact of Cognitive Ability and Non-Cognitive Ability on the Return of Youth Labor Income. Chinese Youth Research, No. 2, 56-64.

[16] Xu, D.D. (2017) How Do Universities Change the Fate of the Students: Family Poverty, Non-Cognitive Ability and First-Time Income. Society, No. 4, 90-118.

[17] He, Y.Z. and Wang, X.J. (2017) Educational Return on Cognitive and Non-Cognitive Ability: An Empirical Study Based on the International Adult Competency Assessment Project. Economics and Management Research, No. 5, 66-74.

[18] Li, L., Zhao, W. and Bian, W.J. (2017) An Empirical Study of the Influence of Family Background on Non-Cognitive Ability. Educational Development Research, No. 1, 51-58.

[19] Luo, F. and Guan, J. (2017) Analysis of the Influence of Family Background and Cultural Capital on Children's Non-Cognitive Ability. Contemporary Education Science, No. 9, 91-96.

[20] Zhang, D., Zheng, L. and Yu, X. (2018) Research on the Influence of Preschool Education on Students' Non-Cognitive Ability. Educational Science Research, No. $278,39-45$.

[21] Anger, S. and Schnitzlein, D.D. (2017) Cognitive Skills, Non-Cognitive Skills, and Family Background: Evidence from Sibling Correlations. Journal of Population Economics, 30, 591-620. https://doi.org/10.1007/s00148-016-0625-9

[22] Yang, Z.C. (2018) Family Background and Student Development: The Mediating Role of Parental Participation and Self-Educational Expectations. Educational Economic Review, No. 13, 63-84.

[23] Li, L. and Zhao, W.L. (2017) Research on the Influence of Family Background and Cultural Capital on Cognitive Ability and Non-Cognitive Ability. Dongyue Theory, No. 4, 142-150.

[24] Cunha, F., Heckman, J.J., Lochner, L. and Masterov, D.V. (2006) Interpreting the Evidence on Life Cycle Skill Formation. Handbook of the Economics of Education, 1, 697-812. https://doi.org/10.1016/S1574-0692(06)01012-9

[25] Wang, H.M., Wu, Y.X. and Huang, C. (2017) Family Socioeconomic Status, Preschool Education and Adolescent Cognition-Non-Cognitive Ability. Youth Studies, No. 6, 50-61.

[26] Yao, W. and Ye, Z. (2018) Family Background, Quality of Education and Formation of Students' Ability-Multilayer Linear Model Analysis Based on CEPS. Contemporary Education and Culture, No. 58, 75-84.

[27] Xiao, S.R. and Xu, G.X. (2009) Gender Differences in Family Environment Affect- 
ing Adolescents' Personality Traits. Psychology, 29, 71-75.

[28] Stevenson, D.L. and Baker, D.P. (1992) Shadow Education and Allocation in Formal Schooling: Transition to University in Japan. American Journal of Sociology, 97, 1639-1657. https://doi.org/10.1086/229942

[29] Bray, M. (1999) The Shadow Education System: Private Tutoring and Its Implications or Planners. Fundamentals of Educational Planning No. 61.

[30] Zhu, X. (2013) Shadow Education and Cultural Capital Theory in Education Globalization. Tsinghua University Education Research, No. 4, 51-55.

[31] Xue, H.P. and Li, J. (2016) Family Capital, Shadow Education and Social Reproduction. Education Economic Review, No. 4, 62-83.

[32] Li, J.L., Hu, Y.M. and Fan, W.F. (2016) Family Background, Shadow Education and Student Achievement: An Empirical Study Based on the Wisconsin Model. Education Economic Review, 70-89.

[33] Li, B. (2018) Is Education Tutor Really Effective?-Based on the Perspective of Academic Performance and Non-Cognitive Development. Beijing Social Sciences, No. $182,40-49$. 